\title{
The Risk and Regulation of Standard Terms
}

\author{
LI, Haiyang \\ Department of Clinical Medicine, Xuzhou Medical University, Xuzhou 221004, Jiangsu, P. R. China \\ lihy@xzhmu.edu.cn
}

Keywords: Standard Sterns; Risk Prevention; Regulation

\begin{abstract}
Standard terms are widely used in modern society, but the risks are obvious. This article first expounds the definition of the standard terms and the characteristics of the four aspects. It also analyzes the possible risks of the standard terms: the standard contract providers are likely to expand their own rights and reduce their responsibility, while limiting the rights and raising the responsibility of their counterparts. In view of the shortcomings of the current standard terms risk prevention in China, it discusses the measures from four aspects, including legislation.
\end{abstract}

\section{Introduction}

Because standard terms have many advantages such as improving transaction efficiency, it is widely used in economic activities. This is the inevitable tendency of modern economy and an important phenomenon in the development of contract law in the 20th century. At the same time, it is not uncommon that the providers of standard terms infringe the rights of their counterparts through the standard terms. The effective measures to reduce risks have long been one of the important issues.

\section{Definition and characteristics of the standard terms}

Within different legal systems, in different countries within the same legal system, and even among different schools in the same country at different times, the dimensions of examining the standard terms are different. The differences in the naming and definition of the standard terms are obvious. In China, with the deepening of research and the enactment of the "Contract Law of the People's Republic of China”, the disputes about the definition and extension of the standard terms have been moderated to some extent. The so-called standard terms refers to the contract terms pre-drawn by the parties to the contract, and the term(s) are not or cannot be negotiated with the other party at the time of conclusion of the contract. In general, there are two forms of standard terms in a contract: one is that some terms of the contract are standard terms, and the other is that all terms of the contract are standard terms. [1]

The standard terms have the following characteristics: first, it has pending feature. The content of the standard terms is the text that has been prepared by the parties before the parties conclude the contract rather than after consultation with the other party. Only a signature is required. Second, it has a subordinate status. The counterpart only has the right to totally accept or reject and comply with the provider of the standard terms rather than expressing his or her will freely. Third, it has stable content. The standard terms are generally applicable to unspecified counterparts who will sign a contract with the contract provider and do not change from one to the other. Fourth, it has repeated frequency. This is a feature of most standard terms, indicating the efficiency of the standard terms. However, the non-repeated standard terms also exist.

\section{The possible risks of the standard terms}

The standard terms is widely used in modern society because it is able to reduce transaction costs, improve transaction efficiency, enhance transaction security, and supplement legal regulations. In the use of standard terms, the existence of risk cannot be ignored, such as the destruction of the 
principle of freedom of contract and the deviation from the principle of good faith. [2] In order to effectively regulate risks, it is necessary to have a comprehensive understanding of risks. The main risks of the standard terms are as follows.

\subsection{Expanding the rights of standard contract provider}

Whether in the Anglo-American or Chinese legal system, once a contract is established, it is binding both parties, who must strictly abide by the contract. At the same time, some standard terms providers give themselves the right to arbitrarily cancel the change in contract, stop the performance of the contract or delay the performance of the contract within an indefinite period of time, even if the counterpart is not at fault. This makes it easy for the standard contract provider to evade responsibility during the performance of the contract, and the risk of the contract as well as the cost to the counterpart fall on the counterpart.

\subsection{Reducing the responsibility of the standard contract provider}

The standard terms provider may add unreasonable terms to reduce the current or pending responsibility are maximize the interests of itself. For example, it is agreed in the contract to choose time and place to perform contract more suitable for the provider, to designate court in the place where the provider operates as a dispute supervision court, or to claim that the provider is only responsible for intentional or serious negligence.

\subsection{Limiting the rights of the counterpart}

The standard terms provider stipulates in the contract that the counterpart waives certain rights or requires the counterpart to exercise the right bound by the provider's consent, such as the provision that "The Item cannot be replaced." Another case might be that the counterpart is not allowed to change or terminate the contract. The right of the counterpart to claim compensation for breach of contract is restricted, and the counterpart has no right to interpret the contract. Moreover, it even limits or exclude the counterpart to seeking for legal relief.

\subsection{Raising the responsibility of the counterpart}

The standard terms provider arbitrarily raises the responsibility of the counterpart in the performance of the contract by expanding the scope of the liability of counterpart and pre-arranging the unreasonable distribution of the risk in the contract. For instance, it is agreed that the counterpart will bear more than the liquidated damages or damages under normal circumstances. The counterpart shall also bear unreasonable liability for breach of contract due to force beyond human control.

\section{The regulation of the standard terms risk}

It can be seen from the risk of the standard terms that it is difficult for the counterparts to completely regulate the risk of the standard terms with their own efforts, and a comprehensive approach must be sought. Mr. WANG, Zejian proposed six ways: adding mandatory regulations to the legislation; strengthening the supervision of the competent authorities administratively or adopting the pre-approval system; examining the effectiveness of the contract by the court; strengthening the pressure of consumer organizations and public opinion; self-discipline of enterprise manufacturers; and promoting the neutral institutions to formulate a model contract. [3] Regulating the risk of standard terms, it is necessary to take advantage of its strength and to operate within the basic principles of civil law. In view of this, the regulation of the standard terms can be implemented in the following ways.

\subsection{Legislative regulation}

Legislative regulation is the most direct and effective method. At the international level, there are two main types of legislative regulation on the standard terms: one is separate legislation, such as 
the "General Trading Conditions Act" in Germany and the "Unfair Contract Clauses Act" in the United Kingdom. [4] The second is mixed legislation. For example, in Italy, the standard terms is stipulated in the Civil Code, and in South Korea, it is regulated in a separate law such as Consumer Protection Law. Internationally, the regulation of standard terms is changing from mixed legislation to separate legislation. In China, the legislation on standard terms has just started, and there are still many shortcomings. It is necessary to strengthen the regulation of the risk of standard terms through legislation, especially by speeding up the implementation of separate legislation.

\subsection{Judicial regulation}

The judicial regulation of the standard terms refers to the remedy of judging the effectiveness of the standard terms by the judicial department when the risk of the standard terms arises. It has the characteristics of finality, impartiality and openness. Since the implementation of the Contract Law of the People's Republic of China, the judicial department has the power to review the validity of the possible standard terms in various commercial contracts and consumer contracts. Judicial remedy should be based on the principle of protecting the interests of counterparts. The interpretation of the standard terms should be based on the principle of facilitating the counterparts. The provider of standard terms cannot infringe the interests of the counterparts, only because the standard terms made or approved by the administrative department is not a specific administrative act. The mandatory provisions of laws and regulations and the basic principles such as fairness and integrity established by modern civil law must also be protected.

\subsection{Administrative regulation}

Tracing back in the history of laws, administrative regulation is an early adopted regulatory method. In Germany, industrial authorities implement administrative regulation of standard terms. In Israel, special committees are authorized to review standard terms. Standard terms and administrative regulation have their strengths and weaknesses in terms of professionalism, impartiality, labor and financial input and efficiency, etc. To some extent, they complement each other. In China, the standard terms of important civil economic activities can be applied only after approval by the administrative agency. The administrative agency or its entrusted institution can formulate a model contract. For example, the standard terms of pre-sale contract of commercial housing is strictly managed and specified by administrative agency. Of course, the results of administrative regulation are not final.

\subsection{Other ways}

In addition, there are other ways in legal practice and life practice. The self-discipline of industrial associations is of low cost and wide coverage, but it lacks powerful constraints. It is difficult for a single consumer to impose restrictions on various aspects, so the supervisory role of the consumer protection organization should be strengthened and the right to appeal can be considered. In the Internet age, the role of news media supervision has become more prominent, especially the new media. It has responded sharply, spread rapidly, and aggregated effectively. These approaches, as a complement to the aforementioned regulations, also play a very active role.

\section{Summary}

This paper analyzes the possible risks of the standard terms: the standard contract provider is likely to expand its own rights and reduce its responsibility, while the counterpart's rights are limited, and the responsibility is raised. In view of the current deficiency of the risk prevention for standard terms in China, the corresponding measures are put forward, namely, improving the legislative, judicial regulation and administrative regulation. 


\section{Acknowledgements}

This research was financially supported by Jiangsu University Brand Professional Construction Project Phase I Project Funding (Grant NO. PPZY2015B161) and Jiangsu University Philosophy and Social Science Fund Project Funding (Grant NO. 2017SJB0984).

\section{References}

[1] JIANG, Ping. Interpretation of the Contract Law of the People's Republic of China, Beijing: China University of Political Science and Law Press, 1999.

[2] WANG, Youlian. Logic Analysis of Judicial Regulation of Format Terms, Hebei Law, vol. 3, pp. 64-74, 2017.

[3] WANG, Zejian. Research on Civil Law and Cases, Beijing: China University of Political Science and Law Press, 1998.

[4] WANG, Quandi; CHEN, Qian. Regulation of Format Terms in German Law, Comparative Law Research, vol. 1, pp. 62-71, 2004. 